\title{
Correlatos entre las Noches áticas y el Quijote. Una lectura crítica del cervantismo*
}

\author{
FRANCISCO GARCÍA-JURADO**
}

\begin{abstract}
Resumen
No hay prueba alguna de que Cervantes leyera las Noches áticas de Aulo Gelio ni tampoco aparecen referencias explícitas al autor latino en ninguna de las obras de aquel. Sin embargo, resultaría improbable que un libro tan variado como el de Gelio, con tantos lugares comunes transmitidos gracias a intermediarios tales como Fray Antonio de Guevara, Pedro Mexía, Erasmo o Alciato, no tuviera alguna incidencia, por indirecta, irónica o dispersa que esta fuera, en el mismo Quijote. Este trabajo revisa, sobre todo a partir de la necesaria lectura crítica de las notas al Quijote de Clemencín, Schevill-Bonilla, Rodríguez Marín y Rico, aquellos pasajes cervantinos donde puede considerarse que hay un correlato geliano, al tiempo que propone alguno nuevo. De manera general, ciertos lugares comunes y aforismos configuran y definen este estado de cosas. El presente trabajo supone, asimismo, una microlectura humanística de la obra cervantina.
\end{abstract}

Palabras clave: Aulo Gelio; Quijote; correlato; notas.

Title: Correlates between the Attic Nights and Don Quixote. A Critical Reading of Cervantism

\footnotetext{
Abstract

Cervantes has not probably read the Attic Nights by Aulus Gellius, in fact, there is no explicit reference to the Roman writer in any of his works. However, it would be unlikely that a book as varied as that of Gellius, with so many common places transmitted thanks

* El presente estudio se adscribe al proyecto de investigación «Diccionario Hispánico de la Tradición Clásica (DHTC)». Proyecto FFI2017-83894-P financiado por el Ministerio de Ciencia, Innovación y Universidades. Quede expreso nuestro agradecimiento a María José Barrios Castro por su lectura crítica de este trabajo, así como a los informantes desconocidos.

** Universidad Complutense de Madrid. pacogj@ucm.es / ORCID iD: https://orcid.org/00000002-3106-1178
} 
to intermediaries such as Fray Antonio de Guevara, Pedro Mexía, Erasmus or Alciatus, had no incidence, although indirect, ironic or dispersed, in the same Quijote. This paper reviews, especially from the necessary critical reading of the quotations to the Quijote by Clemencín, Schevill-Bonilla, Rodríguez Marín and Rico, those Cervantine passages where it can be considered that there is a correlate with Gellius, while proposing a new one. In general, certain common places and aphorisms configure and define this state of affairs. The present work also implies a humanistic micro-reading of the Cervantine work.

Keywords: Aulus Gellius; Quixote; Correlate; Quotations.

\section{Cómo citar este artículo / Citation}

García-Jurado, Francisco. 2021. «Correlatos entre las Noches áticas y el Quijote. Una lectura crítica del cervantismo». Anales Cervantinos 53: 53-84. https://doi.org/10.3989/anacervantinos.2021.002

\section{Más ALLÁ de La LeCtura. La RECEPCión RENACENTiSTA DE LAS NOCHES ÁTICAS}

En su libro Cervantes, la invención del Quijote, Arturo Marasso llega a referirse en cierto momento a Aulo Gelio como un autor «necesariamente leído y del que algo aprendió Cervantes» (Marasso 1954, 64). Estamos conformes con la segunda parte del aserto, en el sentido de que Cervantes sí llegó a saber algunas cosas de las Noches áticas compuestas por el escritor latino, pero no hay prueba alguna de que el autor del Quijote llegara a leer tal libro ${ }^{1}$. Así las cosas, cabe plantearse la siguiente pregunta: ¿cómo pudo aprender Cervantes algo de una obra que probablemente no leyó? Este dilema nos trae a la memoria un inquietante libro de Pierre Bayard titulado Cómo hablar de los libros que no se han leído (Bayard 2011), donde su autor, un profesor francés de literatura, considera que la cultura es, en realidad, nuestra capacidad de situar las obras dentro de una biblioteca colectiva por la que nos orientamos idealmente, al tiempo que establece cuatro maneras básicas de «no-lectura»: libros que no se conocen, libros que solo se han hojeado, libros de los que hemos oído hablar y, finalmente, libros que se han olvidado.

1. Somos conscientes de que la cuestión de las, así llamadas, "fuentes literarias de Cervantes" es harto delicada. Ya se refiere a este asunto Marcel Bataillon al tratar acerca del erasmismo de nuestro autor (Bataillon 1998, 799-801). Por lo demás, no se ha encontrado el menor vestigio de Aulo Gelio al reconstruir hipotéticamente la biblioteca de Cervantes (Eisenberg 1987, 271-328) o la ficticia del propio Alonso Quijano (Baker 1997). Véase, asimismo, Solís de los Santos (2016, 106, n. 44). Las reminiscencias cervantinas de Macrobio, autor que tanto debe a Aulo Gelio, señaladas por Navarro Antolín (2006, 172-176) a partir de Franklin O. Brantley, se centran en el comentario al Somnium Scipionis. 
En lo que al presente trabajo respecta, vamos a estudiar de qué manera un autor que no ha tenido que leer necesariamente a otro establece correlatos con la obra de este segundo sin demasiada conciencia de lo que hace, aunque, en cierto sentido, de manera inevitable. Si bien escritas en el siglo II de nuestra era, las Noches áticas (a partir de ahora, N.A.) de Aulo Gelio alcanzan su plenitud lectora en el siglo XVI. Las primeras ediciones impresas tuvieron lugar en Roma (donde se edita la princeps en 1469) y Venecia, y la obra gozó de una extraordinaria difusión durante el siglo XVI gracias a la labor de editores como Gryphius o Stephanus, entre otros, hasta el punto de que se trata de un libro que no es necesario haber leído para conocerlo e incluso citarlo. Esta condición de libro de libros, o de lectura de lecturas, pudimos apreciarla en un trabajo publicado hace ya unos años (García Jurado 2012a). Antes de pasar a ser considerada como una mera fuente de datos, la obra de Gelio se leía en calidad de modelo de aquel género que tanto predicamento tuvo en el siglo XVI: las misceláneas o «silvas de varia lección».

Es posible utilizar ciertos criterios heurísticos que nos ayuden a comprender mejor cómo son los cauces mediante los cuales un libro llega a ser conocido por un autor dado, de una forma directa o indirecta. Se trata de unos criterios que hemos desarrollado en otro trabajo dedicado a la lectura que Jorge Luis Borges llevó a cabo de Aulo Gelio (en este caso, sabemos que Borges sí leyó las N.A.). Nos referimos a los intermediarios entre ambos autores, las pruebas materiales de la lectura, las citas textuales, los lugares comunes, los aforismos y la propia conciencia del género literario, entre la miscelánea y el ensayo, donde se sitúa este tipo de obras. Pasamos a dar breve cuenta de tales criterios:

a. Intermediarios: los dos grandes intermediarios hispanos de las N.A. son Fray Antonio de Guevara y Pedro Mexía, sin menoscabo de otros autores posibles. En el ámbito europeo, Erasmo, gracias a sus adagios, y Alciato, mediante algunos de sus emblemas más conocidos, también contribuyen a esta difusión indirecta.

b. Pruebas materiales: la presencia de las N.A. en las bibliotecas renacentistas es un hecho significativo y notable. El auge de la edición hace posible que podamos presuponer esta prueba material en casos de escritores como Montaigne (Magnien-Simonin 1995) o el Inca Garcilaso (García Jurado 2017a). Aunque en estos casos no contemos con el ejemplar en concreto, podemos indagar acerca de la edición que estuvo más cercana en el tiempo al autor. Emilio Blanco recurre, con buen criterio, a una edición de las N.A. publicada en Venecia en 1517 como la más cercana a la composición del Relox de príncipes de Fray Antonio de Guevara (1529) (Blanco [apud Guevara 1994, LXIII]). En este sentido, cabe decir que la edición que le correspondería temporalmente a Cervantes es la de Stephanus (1585), con la peculiaridad de que en 1609 se publica una nueva edición en Ginebra (Gelio 1609) que aparece entre la primera y segunda parte del Quijote.

c. Citas y paráfrasis extraídas de las $N$. A.: este sería el criterio heurístico que más nos acerca a la «textualidad» de la obra, dado que se podrían valorar 
pasajes que han sido transcritos o incluso traducidos. Significativo es, a este respecto, el texto de Gelio vertido al francés que Montaigne inscribe en uno de sus ensayos, donde refiere una anécdota sobre Plutarco (García Jurado 2017b). Guevara, por su parte, parafrasea de manera creativa textos de Gelio, como el de Androcles y el león.

d. Lugares comunes y tópicos: la obra de Gelio ha sido fuente de historias o anécdotas que se han tornado tópicas, como la de la cortesana Laida o la de Androcles y el león. Más alejados de esa textualidad a la que acabamos de referirnos, los lugares comunes y los tópicos nos remiten al «contenido» de un relato más que a la literalidad de su «forma» o expresión. Resulta, en este sentido, muy significativa la reelaboración que Michel de Montaigne lleva a cabo en su ensayo titulado «De los mentirosos» a partir de lo que Gelio y Pedro Mexía formulan como la diferencia entre «mentir» y «decir mentira» (García Jurado 2012b).

e. Aforismos: los Adagios de Erasmo y los Emblemas de Alciato son ejemplos perfectos de transmisión indirecta de algunos breves pasajes atribuidos a Gelio, «encapsulados» bajo la forma de una sentencia. A manera de pequeñas píldoras, los adagios o emblemas permiten que algunas frases puedan transmitirse de autor en autor convertidas incluso en expresiones más o menos lexicalizadas («Llevarse la palma»).

f. Géneros literarios: esta es la cuestión acaso más delicada del estudio de la lectura de Gelio en el siglo XVI. Montaigne comenzó a leer la miscelánea en clave de «no-ensayo» (García Jurado 2012a, 60-61) y Francis Bacon profundizó en esta línea al definir ya conscientemente el nuevo género. Hay quien ve en ciertos textos de Cervantes, particularmente algunos prólogos, ejemplos de prosa ensayística. Esta reacción ante la miscelánea supone, a su vez, una forma de recepción de la misma.

Naturalmente, no todos estos criterios heurísticos van a mostrarse válidos por igual a la hora de plantear el presente estudio. Serán, de manera particular, los intermediarios, los tópicos y los aforismos los criterios que más útiles nos van a resultar. También conviene señalar, en lo que concierne a la constatación de tales aspectos comunes, el cuidado que debe ponerse a la hora de valorar qué naturaleza tiene esa relación entre las dos obras ${ }^{2}$. Por ello, la idea del correlato parece la más útil y neutra, frente a otras como la de fuente, pues el correlato no implica necesariamente la dependencia de una obra con respecto a la otra ${ }^{3}$. En este sentido, merece la pena que indaguemos un poco más en tal asunto.

2. «Paralelismo de idea y expresión no equivale a fuente o intertexto sino, a lo sumo, al interdiscurso humanista en nuestro caso, definido por Cesare Segre» (Joset 2017, 518).

3. A este respecto, es muy interesante el estudio de Cherchi (1993) acerca de las fuentes en la Silva de varia lección de Pedro Mexía. 


\section{EL CASO DEL QUIJOTE: UNA INCIERTA Y DISPERSA RECEPCIÓN DE LAS $N$. $A$. LAS NOTAS CERVANTINAS}

El ensayo de una lectura del Quijote desde las N.A. de Aulo Gelio conlleva ciertas dificultades hermenéuticas que, lejos de disuadirnos de tal estudio, nos estimulan a llevarlo a cabo. En un principio, cabe señalar dos tipos de correlato:

a. Correlatos ya establecidos por los comentaristas y críticos. Para ello, es esencial el estudio de las notas de los editores u otros estudiosos.

b. Otros correlatos posibles que, si bien por medio de cauces indirectos, pueden establecerse con las N.A.

Con respecto a los primeros (a), no pueden aceptarse, sin más, los correlatos que aparecen dentro de las notas que encontramos en las distintas ediciones del Quijote, pues es preciso llevar a cabo la revisión crítica de las mismas. No compartimos, por ejemplo, el criterio seguido por Antonio Barnés a la hora de partir de las notas de Rodríguez Marín y Rico como medio que permita establecer y cuantificar las referencias a los clásicos en el Quijote 4 . Desde el punto de vista metodológico, consideramos que tales notas deben pasar a ser parte de nuestro objeto de estudio para su revisión crítica, junto con el texto del Quijote como tal. De manera particular, tendremos en cuenta los siguientes grupos de notas dentro de diferentes ediciones del Quijote ${ }^{5}$.

- Clemencín (1967): si bien en sus notas no hay referencias a Gelio, sí las hay a intermediarios entre Gelio y Cervantes como Fray Antonio de Guevara para la referencia a la meretriz Laida (Gelio 1, 8 y Quijote I, prólogo [Rico 2005, 12]).

- Schevill-Bonilla (1928-1941): si bien en sus notas no hay referencias a Gelio, sí las hay a intermediarios como Pedro Mexía para la cuestión de los argumentos recíprocos (Gelio 5, 10 y Quijote II, 51 [Rico 2005, 939]).

- Rodríguez Marín (1947-1949): en sus notas aparecen cuatro referencias a Gelio (Gelio 4, 7 para Quijote I, prólogo [Rico 2005, 7-8]; Gelio 17, 21 para Quijote II, 28 [Rico 2005, 767]; Gelio 18, 2 para Quijote II, 51 [Rico 2005, 939] y Gelio 18, 14 para Quijote II, 74 [Rico 2005, 1104]).

- Rico: aparece una referencia entre las notas a pie de página (Gelio 7, 12, 1 para Quijote II, 2 [Rico 2005, 564]) y otras cinco que solo están en las

4. En lo que respecta a Gelio, Barnés establece cinco «referencias implícitas» (Barnés 2009, 29) a partir de las cuatro veces que Rodríguez Marín recurre a Gelio en sus notas, a las que se suma una de la edición de Rico; sin embargo, a lo largo de su trabajo, no se refiere más que a dos pasajes de Gelio (Barnés 2009, 107 y 153 [Gelio 6, 12, 1] y 201 [Gelio 2, 10]). Al no haber ninguna referencia explícita a Gelio en el Quijote, tales notas, por lo que vamos a ver en este trabajo, ni agotan los correlatos (ya señalados o posibles) con el Quijote ni son del todo correctas. Véase otra crítica a Barnés con respecto a ciertos autores clásicos en Joset (2017, 520-522).

5. Sin menoscabo de la diversidad de ediciones, todas las citas que hagamos al texto del Quijote van a remitir a la edición de Rico para la Real Academia Española (Rico 2005). 
notas del volumen complementario ${ }^{6}$ (Gelio 7, 12, 1 para Quijote II, 2 [Rico 2005, 564] y II, 43 [Rico 2005, 871]; Gelio 5, 10 para Quijote II, 51 [Rico 2005, 939]; Gelio 18, 14 para Quijote II, 74 [Rico 2005, 1104] y Gelio 2, 10 para Quijote II, 74 [Rico 2005, 1104]).

Sin ánimo de agotar el asunto, también tendremos en cuenta los correlatos establecidos en diferentes estudios: los de Palomares Expósito 2008 (Gelio 12, 11, 7 y Quijote I, 1 [Rico 2005, 27]), Ramírez Araujo 1954 (Gelio 1, 3, 20 y Quijote I, 33 [Rico 2005, 332]), Bizzari 2015 a partir de Faselius 1859 (Gelio 3, 6 y Quijote II, 3 [Rico 2005, 568]), y Joset 2017 (Gelio 3, 11, 6-7 y Quijote II, 74 [Rico 2005, 1104]).

Finalmente, en lo que respecta a los correlatos posibles (b), nos referimos a aquellos que no han sido señalados hasta el momento, como el que vamos a proponer en el epígrafe 3.3 (Gelio 12, 11, 7 y Quijote I, 9 [Rico $2005,88])$. No obstante, debe mostrarse una gran cautela a la hora de proponer un nuevo correlato y, en realidad, no es este el aspecto que más nos ha interesado a la hora de llevar a cabo este trabajo, sino la revisión de los correlatos ya establecidos.

A continuación, establecemos los correlatos entre Gelio y el Quijote a partir del análisis de las referencias a las $N$. A propuestas dentro de las notas y estudios cervantinos, al tiempo que presentamos el nuevo correlato posible. Para ello, seguiremos el mismo orden en que tales correlatos aparecen dentro del Quijote.

\section{LA PRIMERA PARTE DEL QUIJOTE}

\subsection{La cortesana Laida}

No sería difícil leer los prólogos de Cervantes en calidad de incipientes ensayos. El escritor guatemalteco Augusto Monterroso expone el asunto de esta forma:

Cervantes es quizá también en nuestro idioma el primer ensayista moderno; y que para confirmar esta insólita aseveración no tiene sino que tomarse la molestia de ir a sus prólogos de las partes Primera y Segunda de Don Quijote de la Mancha, el de las Novelas ejemplares y el de Persiles y Sigismunda, en los que observará muy claramente gran parte de lo dicho aquí sobre este traído y llevado género... (Monterroso 2003, 9).

Tan es así que hay un momento en que, al leer las siguientes líneas de Cervantes dentro del prólogo a la primera parte del Quijote, nos vienen a la mente otros textos prologales que plantean situaciones parecidas:

6. Para las notas del equipo de Francisco Rico, tanto las que aparecen a pie de página en la edición como las que son complementarias, remitimos a Rico 1998. 
Sólo quisiera dártela monda y desnuda, sin el ornato de prólogo, ni de la inumerabilidad y catálogo de los acostumbrados sonetos, epigramas y elogios que al principio de los libros suelen ponerse. Porque te sé decir que, aunque me costó algún trabajo componerla, ninguno tuve por mayor que hacer esta prefación que vas leyendo (Quijote I, prólogo [Rico 2005, 7-8]).

Tales líneas nos animan a recordar un pasaje del «Au lecteur» de Montaigne, donde este declara que no dudaría en ofrecer completamente desnudo no ya su texto, como dice Cervantes, sino su propia persona: «Que si j'eusse esté entre ces nations qu'on dict vivre encore sous la douce liberté des premieres loix de nature, je t'asseure que je m'y fusse très-volontiers peint tout entier, et tout nud» (Montaigne, «Au lecteur» [Montaigne 1992, 9]). La cuestión, por tópica que pueda resultar, nos remonta, asimismo, a la Praefatio de las N.A. de Gelio, a quien leyó Montaigne; el autor latino no habla de desnudez alguna, pero sí de cierta forma de rusticidad (subrustice) que lo ha llevado a dar a su obra un título tan sencillo que únicamente se refiere a las circunstancias de la composición, es decir, a la tranquilidad de la campiña ática durante la noche (Gelio praefatio 10). Más tarde, ya dentro del prólogo de Cervantes al Quijote, aparece el socorrido amigo que aconseja al autor, no sin ironía, acerca de cómo puede dotar de ropajes a su obra, como el recurso a latines memorizados y lugares comunes. Entre ellos, vamos a encontrar la referencia indirecta a Aulo Gelio más notable en el Quijote, que no es otra que la alusión a Lais o Laida, citada junto a otras dos cortesanas de la Antigüedad: «Si tratáredes de ladrones, yo os diré la historia de Caco, que la sé de coro; si de mujeres rameras, ahí está el obispo de Mondoñedo, que os prestará a Lamia, Laida y Flora, cuya anotación os dará gran crédito» (Quijote I, prólogo [Rico 2005, 12]). Schevill-Bonilla anotan que se trata de la alusión a una de las Epístolas familiares de Fray Antonio de Guevara (apunte que siguen las demás ediciones, hasta Rico):

\begin{abstract}
Alusión a una de las Epistolas familiares (1539-45), de fray Antonio de Guevara. De las 85 Epístolas hay una que trata de «mujeres rameras», dirigida a D. Enrique Enríquez, «en la cual el autor cuenta la historia de tres enamoradas antiquísimas, y es letra muy sabrosa de leer, en especial para los enamorados». Las tres son Lamia, Flora y Laida (Schevill-Bonilla 1928, $\mathrm{XV}, 421)$.
\end{abstract}

La expresión «mujeres rameras» pertenece a Cervantes, mientras que Guevara utiliza la más eufemística de «mujeres enamoradas». Sin saberlo, Cervantes se acerca más a Gelio, que nos habla de «meretrices». En cualquier caso, los críticos han omitido señalar que, en lo que atañe a Laida, Guevara ha partido de una anécdota relatada por Gelio, de manera concreta, en su capítulo titulado «Historia in libris Sotionis philosophi reperta super Laide meretrice et Demosthene rethore» (Gelio 1,8)7. Aquí se nos cuenta cómo

7. Seguimos el texto latino de Gelio 1927. 
Demóstenes fue a Corinto para visitar a la meretriz o cortesana Laida y, dado que el precio por disfrutar de sus servicios era abusivo, el orador concluyó diciendo que no había ido a pagar un arrepentimiento tan caro. En la epístola en cuestión, Fray Antonio de Guevara relata esta anécdota:

Después que Layda volvió de las guerras de Italia a Grecia, retráxose a vivir en la ciudad de Corintho, y fué allí tan servida y requestada, que no hubo hombre rico en Asia que a sus puertas no llamase, ni quedó rey ni príncipe que allá no entrase. Aulo Gelio dice que el buen philósopho Demóstenes fué una vez disfrazado desde Grecia a Corintho por la ver, y aun con ella se revolver; y como ella, antes que le abriese la puerta, le enviase a pedir docientos sestercios de plata, respondió Demóstenes: «No quieran los dioses que yo gaste mi hacienda, ni aventure mi persona, en cosa que apenas la habré hecho, cuando della esté arrepentido». Esto pienso que dixo Demóstenes, por lo que dice el Philósopho, es a saber: «Quod omne animal post coitum tristatur» (Guevara, Epistolas familiares 63 [apud Guevara 2004, 395]).

Guevara adapta, por tanto, la historia contada por Gelio e incluso se atreve a añadirle otra frase conclusiva, a manera de moraleja. Puede que no tenga mayor importancia considerar que esta anécdota, transmitida por Guevara de manera tan irónica, remite en última instancia al autor latino, algo que el propio Guevara reconoce. Sin embargo, dentro del contexto más general de las citas que Guevara hace de Gelio a lo largo de su obra, cabría plantear la hipótesis de que aquel haya podido ejercer más veces de intermediario entre Gelio y Cervantes de lo que podríamos suponer. De manera particular, convendría fijarse en la lectura que hace el propio Guevara del pasaje geliano sobre Androcles y el león (Gelio 5, 14). Aun a sabiendas de que estamos ante un tópico, no deja de ser curiosa la afinidad que encontramos en las descripciones que tanto Gelio como Guevara nos dan del león con el que convive Androcles, por un lado, y aquel que don Quijote ordena excarcelar para medirse con él cara a cara:

Se praeter alia omnia leonum, inquit, immanitas admirationi fuit, praeterque omnes ceteros unus. Is unus leo corporis impetu et vastitudine terrificoque fremitu et sonoro, toris comisque cervicum fluctuantibus, animos oculosque omnium in sese converterat (Gelio 5, 14, 9) ${ }^{8}$.

Entre los animales que para aquella fiesta se trujeron, fue un león que cazaron en los desiertos de Egipto, el cual en cuerpo era grande, en edad antiguo, en el aspecto terrible, en el pelear feroz y en los bramidos muy espantable (Guevara, Epistolas familiares 28 [apud Guevara 2004, 156]). ... el león, el cual pareció de grandeza extraordinaria y de espantable y fea catadura (Quijote II, 17 [Rico 2005, 675]).

8. «Admirábase especialmente una manada de leones enormes, entre los que descollaba uno, cuya monstruosa corpulencia, rápidos saltos, terribles rugidos, abultada musculatura y flotantes melenas, asombraban a los espectadores y atraían todas las miradas» (Gelio 5, 14, 9 [apud Gelio 1893, I, 214]). 


\section{2. «Aníbal» o «Ánibal»}

Tras el prólogo a la primera parte del Quijote, nos encontramos con un poema burlesco compuesto en «décimas de cabo roto»o «pies cortados», es decir, con las palabras incompletas a partir de la última sílaba acentuada, aunque no es este el aspecto que nos interesa, sino la aparición de la palabra «Anibal» en el verso 38, sin especificación gráfica de su prosodia:

Qué don Álvaro de Lu-,

Qué Anibal el de Carta-,

Qué rey Francisco en Espa-

Se queja de la fortu-

(Quijote I, preliminares [«Al libro de Don Quijote de la Mancha, Urganda la desconocida»], 16, vv. 37-40 [Rico 2005, 16]).

Es a propósito del problema prosódico de la palabra «Anibal» donde encontramos la primera nota en que Rodríguez Marín establece un correlato entre el Quijote y un texto de Aulo Gelio:

Tan de lejos viene esta prosodia, que el gramático Valerio Probo, según nota Aulo Gelio (Noches áticas, libro IV, cap. vii), «opinaba que debía pronunciarse Hannibâlem, Hasdrubâlem y Halmicârem, como si la penúltima sílaba estuviese marcada con acento circunflejo». Para ello se funda en que así pronunciaron estas palabras Plauto, Ennio y otros escritores antiguos (Rodríguez Marín 1947, I, 49).

El correlato que establece Rodríguez Marín con respecto a Gelio sirve básicamente como información, pero es muy pertinente que nos interesemos por lo que se cita entrecomillado en calidad de texto de las N.A. Cabe preguntarse si se trata de la consulta directa de una traducción o de la nota de algún comentarista. Hemos podido comprobar sin dificultad que la cita proviene de la versión española de Francisco Navarro y Calvo publicada inicialmente en la Biblioteca Clásica en 1893: «El gramático Valerio Probo, uno de los hombres más instruídos de su tiempo, opinaba que debía pronunciarse Hannibâlem, Hasdrubâlem y Hamilcârem, como si la penúltima sílaba estuviese marcada con acento circunflejo» (Gelio 4, 7, 1-2 [apud Gelio 1893, I, 169]). Como luego veremos, este pequeño hallazgo de la traducción de Aulo Gelio utilizada por Rodríguez Marín justifica, asimismo, su forma de citar a Gelio, pues siempre encontramos referencia al libro y al capítulo concreto, pero nunca al parágrafo en cuestión, dado que tal parágrafo jamás aparece referido en el texto español, a diferencia de lo que ocurre si acudimos a una edición moderna del texto latino. La referencia precisa sería, en cualquier caso, Gelio 4, 7, 1-29. Es

9. Valerius Probus grammaticus inter suam aetatem praestanti scientia fuit. Is «Hannibalem» et «Hasdrubalem» et «Hamilcarem» ita pronuntiabat ut paenultimam circumflecteret... (Gelio 4, 7, 1-2). 
interesante hacer notar que Rodríguez Marín fue el primer estudioso cervantino que recurrió a esta añeja versión española de Aulo Gelio, la primera y única disponible hasta el siglo XXI, algo que explica, pues, tanto su manera de citar la obra (libro y capítulo, sin especificación de parágrafo), como la propia posibilidad de acceder a su contenido, pues no todos los comentaristas han estado dispuestos a comprobar, tal como hace Rodríguez Marín, lo que están citando ${ }^{10}$. De esta forma, y aunque resulte sorprendente, debemos considerar que la ocurrencia de esta cita de Aulo Gelio dentro de una de las más importantes ediciones cervantinas (no será la única cita, por cierto), si bien en una nota a pie de página, convierte la versión española de Navarro y Calvo en una inesperada prueba material para nuestro estudio.

\section{3. "La verdad, cuya madre es la historia»}

La verdad como una realidad revelada a lo largo de la historia o del tiempo constituye una idea tópica que tiene mucho que ver con la propia experiencia humana, de manera que nos ayuda a comprender el pasado, actuar en el presente y estar advertidos con respecto al porvenir. En el caso concreto de la verdad entendida como hija de la historia, estamos ante un conocido pasaje cervantino al que Jorge Luis Borges, en su prosa titulada «Pierre Menard, autor del Quijote», le confirió, de forma inusitada y deliberada, un anacrónico sentido pragmatista (Borges 1989, I, 449). El pasaje cervantino en cuestión es el siguiente: «... no les hagan torcer del camino de la verdad, cuya madre es la historia, émula del tiempo, depósito de las acciones, testigo de lo pasado, ejemplo y aviso de lo presente, advertencia de lo por venir» (Quijote I, 9 [Rico 2005, 88]). Diego Clemencín estableció una esencial relación causal de este pasaje con el De oratore de Cicerón (De oratore 2, 9, 32), de manera que esta «fuente», concebida en el sentido más decimonónico, ha pasado ya a los posteriores comentarios. Podemos verlo, significativamente, en la edición de Rico:

La definición de historia está construida sobre el esquema de Cicerón, convertido en tópico: «Historia vero testis temporum, lux veritatis, vita memoriae, magistra vitae, nuntia vetustatis» (De oratore, II, IX, 36); nótese, sin embargo, el desvío que imprime C[ervantes] (Rico 1998, 110.46).

10. Arturo Marasso $(1954,64)$ también acude puntualmente a esta versión hispana de Aulo Gelio, muy difundida en Argentina, cuando, a la hora de explicar el nombre de «Espartafilardo del Bosque» (Quijote I, 18 [Rico 2005,159]), recurre a un pasaje de las N. A. (Gelio 17, 3) donde Gelio diserta acerca del origen de la palabra «esparto». En concreto, Marasso cita el texto siguiente: «Los griegos empleaban el cáñamo, el lino y otras materias vegetales: de aquí el nombre de sparta» (Gelio 17, 3, 3 [apud Gelio 1893, II, 179]). Acerca del método de Marasso, véase Schwartz 2005. 
Asimismo, dentro de las notas complementarias, se incorpora la referencia al citado cuento «Pierre Menard» de Borges:

Para la definición de historia, CL, VG, Riley [1962/66:270], Avalle-Arce [1975:24].

Borges [1944/80] comenta: «La historia, madre de la verdad; la idea es asombrosa... La verdad histórica, para él, no es lo que sucedió; es lo que juzgamos que sucedió. Las cláusulas finales -ejemplo y aviso de lo presente, advertencia de lo por venir-son descaradamente pragmáticas» (Rico 1998, nota complementaria a 110.46).

Sin embargo, en lo que respecta a este pasaje cervantino, ningún comentarista, que sepamos, ha visto el posible correlato con un texto de Gelio. Así pues, y sin menoscabo alguno de la influencia ciceroniana propuesta por Clemencín y aceptada plenamente por la crítica, la idea concreta de filiación que se establece entre la verdad y la historia nos lleva a hacer una propuesta de correlato con este conocido aforismo transmitido por Aulo Gelio, Veritas filia temporis, que, significativamente, adquirió una nueva vida a la luz del empirismo de Francis Bacon (Recte enim veritas temporis filia dicitur, non auctoritatis [Bacon, Novum Organum I aph. 84 apud Bacon 1803, 58]) $)^{11}$, aunque merece la pena recordarlo en su contexto originario, dada la nueva y curiosa reminiscencia cervantina que se nos aporta en él: «Otro poeta, cuyo nombre no recuerdo, ha llamado a la verdad hija del tiempo» (Gelio 12, 11, 7 [apud Gelio 1893, II, 45]) $)^{12}$. Ciertamente, autores como Palomares Expósito han visto en esta falta de memoria de Gelio, al no recordar el nombre del poeta que acuñó la frase sobre la verdad, un parecido con el propio comienzo del Quijote (Quijote I, 1 [Rico 2005, 27]) ${ }^{13}$, algo que, en nuestra opinión, también tendría que ver, de manera precursora, con cierta «coquetería de la vacilación» (Mainer 1996, 20) que luego terminan mostrando los cultivadores del ensayo moderno ${ }^{14}$. Si regresamos a la cita de Gelio como tal, no es difícil encontrarla en autores ya referidos en calidad de intermediarios, como es el caso de Fray Antonio de Guevara al comienzo de su Relox de príncipes, quien reproduce el aforismo y declara su fuente geliana:

11. El asunto, por lo demás, nos lleva al problema de la verosimilitud en la ficción literaria (Barbagallo 2001). Bausi revisa el aforismo en Maquiavelo como parte de la cultura de su tiempo (Bausi 2016).

12. Alius quidam veterum poetarum, cuius nomen mihi nunc memoriae non est, Veritatem Temporis filiam esse dixit (Gelio 12, 11, 7).

13. «También aquí los clásicos resuenan, desde el cuarto de los Discursos Sagrados de Publio Elio Aristides Teodoro hasta aquello de Aulo Gelio (Noctes Atticae, XII, 11, 7) (Palomares Expósito $2008,261)$. Por su parte, Solís de los Santos apunta igualmente al comienzo del Quijote en su comentario bibliográfico a un incunable de Aulo Gelio: «Al brindarnos el memorable lema de veritas temporis filia (la verdad, hija del tiempo), lo atribuye a cierto poeta antiguo de cuyo nombre no puede acordarse» (Solís de los Santos 2012, 351).

14. Montaigne, sin ir más lejos, no se cansa de hablar acerca de su falta de memoria (Bayard 2011, 70-71). 


\begin{abstract}
Viniendo, pues, al propósito, no nos podemos quexar los que somos agora como se pudieran quexar muchos de los que fueron antes, pues la verdad, la qual dize Aulo Gelio ser hija del tiempo en este postrero tercio del mundo, nos aya declarado muy por estenso todos los errores de que nos hemos de guardar y todas las verdaderas doctrinas que hemos de seguir. ¿Qué ay ya que ver que no esté visto? ¿Qué ay ya que descubrir que no esté descubierto? ¿Qué ay ya que leer que no esté leýdo? ¿Qué ay ya que escrevir que no esté escripto? ¿Qué ay ya que saber que no esté sabido? (Guevara, Relox de príncipes, argumento [apud Guevara 1994, 68]).
\end{abstract}

En este sentido, hemos pensado en la posibilidad de tal correlato debido a la difusión alcanzada por la frase de Gelio en la propia cultura humanística, a la manera de lo que ocurre con otros correlatos que vamos a seguir analizando a continuación.

\title{
3.4. Usque ad aras
}

El dilema moral de hasta dónde es lícito actuar en beneficio de un amigo se expresa con el aforismo usque ad aras [amicus], que circuló en latín por los vericuetos de la cultura humanística y que aparece en la obra de Cervantes: «... como dijo un poeta, «usque ad aras», que quiso decir que no se habían de valer de su amistad en cosas que fuesen contra Dios» (Quijote I, 33 [Rico 2005, 332]). Más allá de la imprecisión de que Cervantes hace gala al atribuir la frase a un poeta, el correlato con Aulo Gelio ha sido apuntado de manera concreta por Ramírez Araujo (1954) ${ }^{15}$, quien propone a Erasmo como intermediario. Estaríamos, pues, ante un aforismo transmitido por Erasmo en sus Adagios (III. II. $10=2110)$, si bien a partir de Plutarco, que escribe $\mu \varepsilon ́ \chi \rho 1 ~ \tau o \tilde{~}$ ßouoṽ (Plutarco, Moralia 186C), es decir, «hasta el altar», pero que, según Erasmo, Gelio reescribe como $\mu \varepsilon ́ \chi \rho \imath ~ \beta \omega \mu \tilde{\omega} \nu$ «hasta los altares» (Oportet me commodare amicis, sed usque ad aras. Ita refert Gellius). Conviene, no obstante, que recuperemos el pasaje de Erasmo en cuestión:

\section{Usque ad aras amicus}

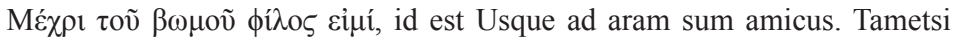
non est huius instituti quaelibet apophthegmata colligere, tamen hoc ita commode dictum et specie usque adeo proverbiali, praeterea sic a magnis celebratum auctoribus, ut merito videatur in hunc ordinem coptandum. Responsum est autem a Pericle, quem cum amicus quispiam rogaret, ut in

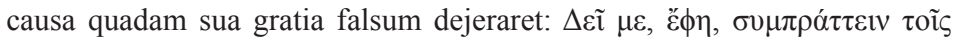
$\phi \dot{i} \lambda o r \varsigma, \dot{\alpha} \lambda \lambda \grave{\alpha} \mu \dot{\varepsilon} \chi \rho \imath \beta \omega \mu \tilde{\omega} v$, id est Oportet me commodare amicis sed usque

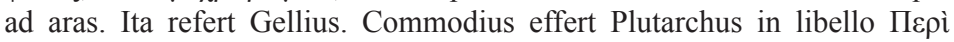

15. Para el contexto de la cita y su reutilización por Erasmo véase, además de Ramírez Araujo 1954, Gendrickson 1957. Más recientemente, Fuente Marina (2019, 132-133). 


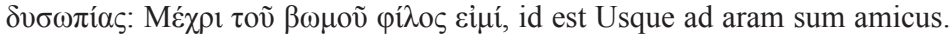
Admonet proverbium nonnunquam, quo consulamus amicorum commodis eorumque voluntati morem geramus, fas videri paululum a recto deflectere, verum eatenus, ne propter hominem amicum numinis reverentiam violemus. Olim jurantes aram manu contingebant. Porro quatenus et quousque sit ab honesto deflectendum amici causa, copiose docteque disputat Aulus Gellius libro Noctium Atticarum primo, capite tertio (Erasmo, Adagia 2110 [apud Erasmo 2001, 68-69]) ${ }^{16}$.

Sin embargo, Gelio escribe algo distinto con respecto a lo que afirma y cita Erasmo, pues no utiliza la palabra «altares», sino «dioses»:

Pericles, aquel ateniense de tan preclaro ingenio, cuyo espíritu estaba adornado con toda clase de conocimientos, con un solo rasgo derramó más luz en esta obscura cuestión. Un amigo suyo le pidió que jurase en falso en favor suyo, y le contestó con este verso:

«Todo debo sacrificarlo a mis amigos, excepto los dioses».

(Gelio 1, 3, 20 [apud Gelio 1893, I, 19]) ${ }^{17}$.

Claramente se trata de un error de memoria de Erasmo a la hora de transcribir, pero esto nos permite observar cómo los errores terminan formando parte de la tradición, pues, aunque la expresión usque ad aras amicus no es la que escribió Gelio, dado que jamás la expresó en latín ni recurrió al término «altares», el desliz de Erasmo termina transcendiendo ${ }^{18}$.

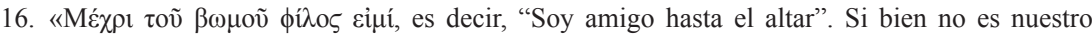
propósito recoger cualquier apotegma, sin embargo, este se dice tan apropiadamente y con apariencia proverbial desde hace tanto tiempo, y es, asimismo, celebrado de tal forma por grandes autores, que parece que debe ser aceptado en esta colección merecidamente. Pericles fue quien lo dio como respuesta, al rogarle un amigo que en cierto proceso judicial jurara en falso a su favor: $\Delta \varepsilon \tilde{\imath} \mu \varepsilon$, $\check{\phi} \phi \eta$,

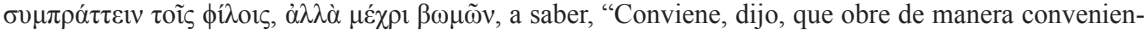
te para mis amigos, pero hasta los altares". Así es como lo refiere Gelio. De forma más apropiada lo

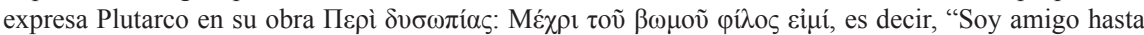
el altar". El proverbio nos advierte de que alguna vez, a fin de que miremos por los intereses de los amigos y actuemos conforme a su voluntad, parece apropiado que nos desviemos un poco de lo justo, pero no más allá de violentar el respeto a los dioses a causa de un mortal, por amigo que sea. En otro tiempo, los que juraban tocaban el altar con su mano. Por lo demás, hasta dónde y hasta cuándo hay que apartarse de la honradez a causa de un amigo, lo trata con amplitud y saber Aulo Gelio dentro del libro primero de las Noches áticas, en su capítulo tercero» (trad. de F. García Jurado).

17. Pericles ille Atheniensis, vir egregio ingenio bonisque omnibus disciplinis ornatus, in una quidem specie, set planius tamen quid existimaret professus est. Nam cum amicus eum rogaret ut pro

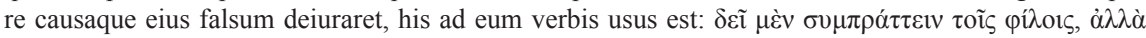
$\mu \varepsilon ́ \chi \rho ı ~ \tau \tilde{\omega} \nu \theta \varepsilon \tilde{\omega} \nu$ (Gelio 1, 3, 20). Nótese que Erasmo recurre a $\beta \omega \mu \tilde{\omega} \nu$ en lugar del correcto $\tau \tilde{\omega} \nu \theta \varepsilon \tilde{\omega} v$. Por su parte, el uso de $\mu \varepsilon$ (en lugar de $\mu \varepsilon \dot{\varepsilon}$, que encontramos en la ediciones modernas de Gelio) supone, sin embargo, la lectura esperable en las antiguas ediciones de las $N$.A. Esta antigua lectura

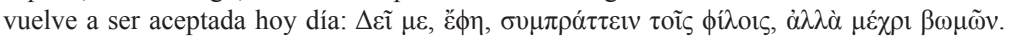

18. Ramírez Araujo lo expone de la manera siguiente: «Erasmo fue en efecto quien lo popularizó al incluirlo en su obra no sin cierto recelo que él mismo confiesa. Plutarco en su[s] Morales atribuye por primera vez a Pericles estas palabras sobre los límites de la verdadera amistad. Aulo Gelio las copia en sus Noches Áticas con una variante que Erasmo no reproduce en su glosa junto con la frase de Plutarco, pero que afecta a la forma latina de la sentencia» (Ramírez Araujo 1954, 224). También habla de ello Bizarri en su Diccionario de paremias cervantinas: «Este refrán se remonta a 


\section{LA SEGUNDA PARTE DEL QUIJOTE}

\subsection{El vestido de César}

Con respecto a Julio César, hay un lugar común que se refiere a su peculiar atuendo, entre afeminado y desceñido. De manera concreta, dos autores latinos, Suetonio en su Vida de Julio César (Julio César 45, 3) y Macrobio en sus Saturnales (Saturnales 2, 3, 9), nos transmiten que Lucio Cornelio Sila advertía de que había que desconfiar de aquel, pues iba con la ropa desceñida, al tiempo que Macrobio añade otra anécdota relativa a Cicerón, que confiesa que se sintió confundido por la falta de compostura de César, de manera que prefirió tomar partido a favor de Pompeyo. Es oportuno que leamos ambos testimonios:

Cuentan que [i.e. Julio César] llamaba también la atención por su forma de vestir, pues usaba siempre la túnica de los senadores, pero con mangas provistas de una franja, que le llegaban hasta las manos, y ceñía esta prenda con un cinturón muy holgado. Esto explica la frase de Sila al aconsejar reiteradamente a los optimates «que desconfiaran de un mozalbete con la cintura floja» (Suetonio, Julio César 45, 3 [apud Suetonio 1964, 39]).

El traductor de este pasaje de Suetonio, Bassols de Climent, ofrece en nota a pie de página una aclaración sobre la manera de vestir de César que más adelante nos resultará muy útil: «Las mangas largas adornadas con franjas solían ser por lo general llevadas por hombres de costumbres afeminadas. Cf. GELL. 7, 12, 1» ${ }^{19}$ (Bassols [apud Suetonio 1964, 39, n. 2]). Como puede deducirse, la referencia a Aulo Gelio sirve de apoyo para la caracterización de César como hombre afeminado, dado que usaba túnicas con mangas. El texto de Macrobio, por su parte, nos refiere también la anécdota relativa a Cicerón:

También contra César apretó sus dientes la mordacidad de Cicerón. En efecto, en primer lugar, tras la victoria de César, cuando éste le preguntó

Plutarco en sus Morales quien a su vez lo atribuye a Pericles; también Aulio (sic) Gelio lo reproduce en sus Noches Áticas. Fue incluido por Erasmo en sus famosos Adagia (Lib. II) y de allí se popularizó en los siglos XVI y XVII; su difusión fue tal que Lope de Vega lo castellaniza: "Yo soy amigo vuestro hasta las aras. ¿En qué os sirvo?” La Dorotea (act. V, esc. 3, 366) y Baltasar Gracián lo diluye: "Bien se ve, piénsalo mucho antes de comenzar una amistad, pero una vez confirmada, hasta las haras" El Criticón (II, 71). No lo registraron los paremiólogos clásicos, salvo Correas, quien, además, ofrece otra versión: "Amigo hasta el altar, es amistad" Vocabulario (A 1692). Comentarios: "Amigo hasta el altar, es amistad. Que la amistad no ha de contradecir ni perturbar la religión; parece al latino: Amicus usque ad aras" Correas, Vocabulario (A 1692). Cervantes utiliza este refrán en varias ocasiones. En todas el sentido es para indicar que la amistad entre los amigos debe ser infinita, salvo si va contra Dios. Ramírez Araujo consideró este refrán como una clara influencia erasmista, si bien no se puede indicar su procedencia segura, en especial porque hemos visto que en la época de Cervantes el viejo adagio latino ya había sido traducido y se difundía popularmente en versiones romances» (Bizzarri 2015, s. v.).

19. Como luego tendremos ocasión de ver, la cita a las $N$. A. no es del todo correcta en lo que respecta a la adscripción al libro séptimo. 
por qué se había equivocado en la elección de bando, replicó: «La manera de ceñir la toga me hizo errar». Y bromeaba a costa de César, quien ceñía la toga de tal manera que caminaba con aire afeminado, arrastrando el borde, hasta el punto de que Sila, como si previera el futuro, dijo a Pompeyo: «Guárdate de aquel joven que ciña mal su toga» (Macrobio, Saturnales 2, 3, 9 [apud Macrobio 2010, 272-273]).

El texto de Macrobio incide únicamente en el hecho de que César iba mal ceñido, pero no en la cuestión de las mangas largas, como hacía Suetonio. Ambas anécdotas, la relativa a Cicerón y la de Sila, aparecen reunidas igualmente por Fray Antonio de Guevara en su Relox de príncipes $^{20}$ :

Fue Julio César en su cuerpo tan mal ataviado, que después de la batalla de Pharsalia dixo un vezino romano al gran orador Tulio: «Dime, Tulio, ¿por qué tú, siendo tan sabio seguiste las parcialidades de Pompeyo y no alcançaste que Julio César avía de ser señor y monarcha del mundo?». Respondió a estas palabras Tulio: «Dígote de verdad, amigo, que a Julio César ver como le vi en la mocedad tan mal ceñido me hizo tenerle en poco». Mejor le conoció el viejo de Silla, el qual, como veýa a Julio César andar mal ceñido y peor ataviado siendo moço, muchas veces decía Silla en el Senado: «Guárdaos de este moço mal ceñido, porque si no le atajan los passos con el tiempo, éste ha de matar y acocear al Pueblo Romano» (Guevara, Relox de príncipes 1, 41 [apud Guevara 1994, 346]).

También recoge ambas anécdotas Huarte de San Juan en su Examen de Ingenios:

El desaliño de Julio César engañó grandemente a Cicerón. Porque preguntándole, después de la batalla, la razón que le había movido a seguir las partes de Pompeyo, cuenta Macrobio que respondió: praecinctura me fefellit; como si dijera: «engañóme ver que Julio César era un hombre desaliñado y que nunca traía pretina», a quien los soldados, por baldón, le llamaban ropa suelta. Y esto le había de mover para entender que tenía el ingenio que pedía el consejo de la guerra; como lo atinó Sila (cuenta Tranquilo), que viendo el desaliño que tenía Julio César siendo niño, avisó a los romanos diciendo: cavete puerum male praecinctum; como si les dijera: «guardaos, romanos, de aquel muchacho mal ceñido» (Huarte de San Juan, Examen de Ingenios [apud Huarte de San Juan 1989, 538-539]).

Cabe señalar que, si comparamos estos dos últimos textos con los de Suetonio y Macrobio, Guevara y Huarte de San Juan desdibujan el afeminamiento de César para convertirlo en simple desarreglo. La cuestión no resulta baladí, por lo que ahora veremos en el caso de Cervantes. Así las cosas, cuando don Quijote conversa con Sancho o lo aconseja, recurre al personaje de César en dos ocasiones. La primera de ellas resulta una referencia algo ambigua:

20. También recogido por Juan de Salisbury en su Policraticus. 


\title{
4.1.a. «No limpio, ni en sus vestidos ni en sus costumbres»
}

Nos centramos ahora en el siguiente pasaje: «Julio César, animosísimo, prudentísimo y valentísimo capitán, fue notado de ambicioso y algún tanto no limpio, ni en sus vestidos ni en sus costumbres» (Quijote II, 2 [Rico 2005, 564]). Clemencín observa cómo este apunte sobre el arreglo y aseo de César encuentra, si bien parcialmente, su correlato en la noticia del historiador Suetonio:

\begin{abstract}
«Algún tanto no limpio, ni en sus vestidos ni en sus costumbres». En la poca limpieza de costumbres de Julio César conviene con Don Quijote Suetonio; pero no en punto a la de traje. Lejos de asentir Suetonio a lo que Don Quijote dijo de César, lo tachaba á este de petimetre y prolijo en el adorno de su persona (Clemencín 1967, IV, 40).
\end{abstract}

Cabe preguntarse qué entiende Clemencín (y, de paso, qué quiere decir Cervantes) al hablar acerca de la «poca limpieza de costumbres», o, en otras palabras, si se refiere a la suciedad o, más bien, al afeminamiento. De esta manera, lo que Clemencín considera una contradicción quizá no lo sea, pues la poca limpieza en lo que respecta al vestido no tendría que ver con el descuido, sino con lo indecoroso. Nos preguntamos si la expresión «algún tanto no limpio» no es más que una forma eufemística de hablar acerca del afeminamiento de César referido por Suetonio. Rodríguez Marín, por su parte, remite a Pérez del Castillo: «Pérez del Castillo, El theatro del mundo..., fol. 73 vto.: "Los Cartagineses dezían mal de Anníbal porque andaua siempre desabrochado y despechugado el estómago; otros burlauan de Iulio César porque andaua mal ceñido"» (Rodríguez Marín 1948, IV, 75). El testimonio de Pérez del Castillo evita igualmente poner en relación la manera de vestir de César con el afeminamiento, por lo que desvía el asunto hacia la mera burla. Por su parte, en la edición de Rico se apunta a la noticia de Suetonio, a la que se añade la de Macrobio y, sorprendentemente, la referencia a Aulo Gelio que ya antes hemos referido a propósito de Suetonio: «Las noticias parecen proceder de Suetonio (De vita duodecim Caesarum, I, XLV, 5); pero del desaliño de César también hablan Macrobio (Saturnalia, II, 4) y Aulo Gelio (Noctes Atticae, VII, XII, 1)» (Rico 1998, 644.38).

Vemos en esta nota a pie de página cómo se presenta un conjunto de tres autores clásicos configurado por Suetonio, Macrobio y Gelio, citados de manera precisa, si bien esta precisión esconde múltiples errores, pues la manera de citar no responde a las ediciones modernas. En principio, en lo que respecta a la manera de citar a Suetonio, hoy día ya no se hace al «libro I», sino al libro de Julio César (Iul.), y el capítulo 45 de este libro tiene tan solo tres parágrafos, de forma que la cita únicamente puede llegar al parágrafo tercero: "Suet. Iul. 45, 3". Por su parte, la cita de Aulo Gelio, como veremos, también presenta problemas con respecto a las modernas ediciones de las N.A., pues parece haber sido tomada en préstamo de otro lugar sin la comprobación adecuada. 
Volvemos a encontrar a los tres autores latinos en las notas complementarias de la edición de Rico, cuando se especifica ahora, incorrectamente, que tales autores aparecen reunidos por Huarte de San Juan:

CL, RM. Los tres autores clásicos citados los reúne Huarte de San Juan (Examen, pp. 538-539) para demostrar sus virtudes, ingenio y capacidad de mando: «El desaliño de César engañó grandemente a Cicerón... como si dijera: «Engañóme ver que Julio César era un hombre desaliñado y que nunca traía petrina», a quien los soldados, por baldón, le llamaban "ropa suelta". Y esto le había de mover para entender que tenía el ingenio para el consejo de guerra» (Rico 1998, nota complementaria a 644.38).

Huarte de San Juan no se refiere a Gelio en momento alguno, por lo que debemos llamar la atención acerca de esta imprecisión o error en la redacción de la nota. La imprecisión prosigue, asimismo, en el segundo de los pasajes cervantinos que nos interesa:

\section{1.b. «Descompostura y flojedad»}

Es pertinente analizar ahora este otro pasaje: «No andes, Sancho, desceñido y flojo, que el vestido descompuesto da indicios de ánimo desmazalado, si ya la descompostura y flojedad no cae debajo de socarronería, como se juzgó en la de Julio César» (Quijote II, 43 [Rico 2005, 871]). En lo que a ese nuevo pasaje concierne, la correspondiente nota de Clemencín se refiere a Macrobio:

\footnotetext{
Macrobio (Lib. II, Saturnal. cap. 3) cuenta de Cicerón que: Post victoriam Caesaris interrogatus, cur in electione partis errasset, respondit: praecinctura me decepit: iocatus in Caesarem, qui ita toga praecingebatur, ut trahendo liciniam velut mollis incederet: adeo ut Sylla tamquam providus dixerit Pompeio: cave tibi illum puerum male praecinctum.

Acerca del porte personal de Julio César se habló ya en la nota al capítulo 2. ${ }^{\circ}$, citándose a Suetonio (Clemencín 1967, V, 355).
}

En la nota de Clemencín aparece una frase latina referida por Macrobio: praecinctura me decepit, sentencia que cuando es citada por Rodríguez Marín en la nota correspondiente al mismo pasaje varía en el verbo (praecinctura me fefelit), dado que Rodríguez Marín sigue, aunque sin citarlo, a Huarte de San Juan; Rodríguez Marín añade, asimismo, una antigua versión en castellano del pasaje de Suetonio:

De este descuido de César algo había dicho don Quijote en el cap. ii de la segunda parte (t. IV, 75, 11). Y, en efecto, tal desaliño engañó a Cicerón de quien cuenta Macrobio que, preguntado por qué siguió el partido de Pompeyo y no el de César, respondió: «Praecinctura me fefelit». Porque César no gastaba pretina, por lo cual los soldados, por burla, le nombraban Ropasuel- 
ta. Y Suetonio, en Las vidas de los doce Césares, traducción de Jaime Bartholomé (Tarragona, Felipe Roberto, 1596), fol. 18 vto.: «En el vestido fue también muy singular: dicen que siempre vsaua de ropa larga senatoria, llamada laticlauo y bordada por los extremos, y ya que vsasse de pretina, era muy floxamente, de donde aduirtiendo Silla a sus amigos les dezía que se guardasen del muchacho mal ceñido» (Rodríguez Marín 1948, VI, 245).

Veamos ahora las notas correspondientes a este pasaje de la edición de Rico: «Se alude a la costumbre de César, criticada por Cicerón, de llevar un cinturón muy flojo, y a la frase de Sila sobre el futuro dictador: "Desconfiad de ese joven mal ceñido"» (Rico 1998, 973.6). Sobre todo, vayamos a la nota complementaria:

BW, PE, CL. La anécdota está en Macrobio (Saturnales, II, 4), en Suetonio, I, XLV, 5, e incluso en Aulo Gelio, Noctes Atticae, VII, XII, 1; a los tres cita Huarte de San Juan, Examen, pp. 538-539, como ya indicamos arriba (II, 2, 644, n. 38); <Moner [1986a:98]. A. Castro [1925/87: 281-282, 360] señala como fuente inmediata de C. los Apotegmas de Erasmo, pero subraya una máxima similar en Isócrates (Rico 1998, nota complementaria a 973.6).

Cabe preguntarse, una vez más, de dónde sale esta referencia a Gelio tan concreta, dado que hasta se cita el parágrafo (algo que, como ya hemos visto, no recoge Rodríguez Marín en sus referencias a Gelio). La propia nota nos da la clave precisa del origen de la cita, que no es otro que una nota a pie de página que Guillermo Serés había puesto en su edición del Examen de ingenios de Huarte de San Juan, y que dice así: «La referencia de Macrobio está en Saturnalia, II, iv; la de Suetonio en De vita duodecim Caesarum, I, xlv, 5 (cfr. Aulo Gelio, Noctes Atticae, VII, xii, 1)» (Serés [apud Huarte de San Juan 1989, 539, n. 43]). Como podemos comprobar, la referencia a Gelio está entre paréntesis y quizá haya sido tomada, a su vez, de alguna edición de Suetonio, probablemente la de la colección Alma Mater ya citada, o de algún anecdotario. Sin embargo, la referencia a Gelio es incorrecta por varias razones. Como sabemos, Huarte de San Juan tan solo recoge a Macrobio y Suetonio, pues Gelio no es más que un apoyo que los modernos editores introducen para corroborar lo que cuenta Suetonio. Volvamos a la nota de Rico y comencemos comprobando la propia cita de Gelio en él referida: «Equivocación de Servio Sulpicio y de C. Trebacio al tomar el uno testamentum y el otro sacellum por palabras compuestas: que la primera palabra de éstas se deriva de testatio, y la segunda es diminutivo de sacer) (Gelio 7, 12, 1 [apud Gelio 1893, I, 245] $)^{21}$. Es obvio que la cita que acabamos de transcribir no guarda relación temática con el asunto del vestido de César. No obstante, la falta de correspondencia es explicable, pues a partir de las ediciones teubnerianas de Martin Hertz (véase, por ejemplo, Gelio 1871-1877), durante la segunda mitad del siglo XIX, se invirtió el orden de los libros sexto y séptimo. Así las cosas, la referencia correcta y actualizada, de acuerdo a las ediciones modernas de las $N$.A., sería

21. Servius Sulpicius iureconsultus, vir aetatis suae doctissimus, in libro De Sacris Detestandis secundo, qua ratione adductus «testamentum» verbum esse duplex scripserit, non reperio (Gelio 7, 12, 1). 
Gelio 6, 12, 1: «En otro tiempo habría sido vergonzoso para un hombre usar en Roma y en todo el Lacio esas túnicas llamadas, del nombre griego, chiridotae, cuyas mangas cubren todo el brazo y caen sobre la mano hasta los dedos» (Gelio 6[7], 12, 1 [apud Gelio 1893, I, 282]) 22. El pasaje de Gelio, así como la lectura del resto del capítulo donde se inscribe, no sería más que un texto de apoyo de carácter general que, aplicado a la forma de vestir de César, no nos habla tanto acerca de su desaliño como sobre su afeminamiento, aspecto que después ha intentado disimularse transformándolo en mero descuido indumentario. Este correlato entre Gelio y Cervantes sería, pues, muy indirecto, aunque no deja de resultar útil a la hora de ayudarnos a interpretar el correcto sentido del texto cervantino.

\section{2. «Lleva la palma»}

La conocida expresión que relaciona la hoja de la palmera con el triunfo aparece recogida por Cervantes: «Solo vuestra merced lleva la palma» (Quijote II, 3 [Rico 2005, 568]). En su Diccionario de paremias cervantinas, Bizzarri pone en relación esta expresión con Aulo Gelio a partir de una antigua monografía de Faselius dedicada a los proverbios de la antigua Roma (Faselius 1859, s. v. Palmam, qui meruit, ferat):

LLEVARSE LA PALMA. Phrase con que se significa que alguno sobresalió o excedió en competencia de otros, mereciéndose el aplauso general. Lat. Palmam adipisci obtinere (Autoridades, s.v. palma).

Se trata de una antiquísima frase proverbial que Faselius documenta en Aulio Gelio: «Palmam, qui meruit, ferat» Noctis Atticae (Lib. 3, cap. VI). Pese a su extendida antigüedad, y que Faselius sostiene haber sido muy común entre los romanos, no se documenta en España esta frase proverbial hasta Cervantes. El próximo que la incluye es Correas: «Llevar la palma. Es vencer en cualquier cosa» Vocabulario (L1 24). Frase proverbial que dice el bachiller Sansón Carrasco en forma de alabanza a don Quijote para decir que él es el mejor de los caballeros andantes (Bizzarri 2015, s. v. «Llevarse la palma»).

Sin embargo, la expresión latina «Palmam qui meruit ferat», tal como aparece formulada en latín, jamás fue escrita por Aulo Gelio, si bien es verdad que este autor explica el origen de la relación simbólica de la madera del árbol de la palmera con el triunfo:

Singular PROPIEDAD DE LA PALMERA, CUYA MADERA SE LEVANTA Y ENDEREZA BAJO EL PESO CON QUE SE CARGA.

Aristóteles, en el libro VII de sus Problemas, y Plutarco en el VIII de sus Simposiacas, refieren una cosa maravillosa, y es, que la madera de la palmera, cuando se la carga con mucho peso y se la oprime bajo enormes

22. Tunicis uti virum prolixis ultra brachia et usque in primores manus ac prope in digitos, Romae atque in omni Latio indecorum fuit (Gelio 6[7], 12, 1). 
masas, lejos de ceder a la presión que sufre, se levanta encorvándose. Por esta razón, dice Plutarco, se ha tomado la rama de la palmera como símbolo de victoria; porque la cualidad de esta madera es no ceder a la fuerza que la sujeta y oprime (Gelio 3, 6 [apud Gelio 1893, I, 132]) ${ }^{23}$.

La noticia está recogida, igualmente, por Pedro Mexía en su Silva de varia lección, que termina diciendo: «De manera que de aquí paresce vino dar palma a los vencedores» (Mexía, Silva de varia lección 1, 33 [apud Mexía 2003, 236]) ( $c f$. García Jurado 2012a, 54-55). La recepción medieval y renacentista alteró sutilmente este texto de Aulo Gelio, de forma que a partir de la madera como tal se pasó a la idea del árbol completo, como puede verse en el emblema 36 de Alciato (Holford-Strevens 2004, 256-257), cuya «alma» (o imagen) y «cuerpo» (o texto) son muy elocuentes al respecto:

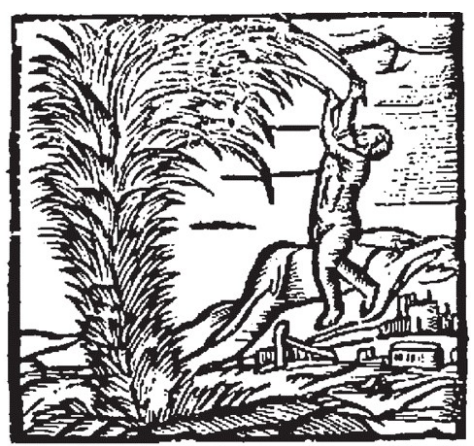

OBDVRANDVM ADVERSVS VRGENTIA

Nititur in pondus, et consurgit in arcum, Quod magis, et premitur, hoc mage tollit onus:

Fert et odoratas bellaria, dulcia glandes ${ }^{24}$, Queis mensas inter primus habetur honos.

I, puer, et reptans ramis has collige: mentis Qui constantis erit, praemia digna feret.

(Alciato, emblema 36 [apud Alciato 1975, 309]) ${ }^{25}$

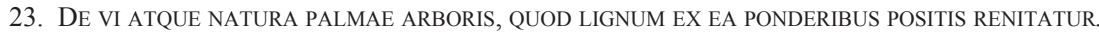

Per hercle rem mirandam Aristoteles in septimo Problematorum et Plutarchus in octavo Symposiacorum dicit. «Si super palmae,» inquiunt, «arboris lignum magna pondera inponas ac tam graviter urgeas oneresque, ut magnitudo oneris sustineri non queat, non deorsum palma cedit nec intra flectitur, sed adversus pondus resurgit et sursum nititur recurvaturque»; «propterea,» inquit Plutarchus, «in certaminibus palmam signum esse placuit victoriae, quoniam ingenium ligni eiusmodi est, ut urgentibus opprimentibusque non cedat» (Gelio 3, 6).

24. Razones métricas hacen que en lugar del fruto específico de la palmera se hable de "bellotas" (glandes), utilizado con el sentido lato de fruto de cualquier árbol (Thesaurus linguae Latinae, s. $v$. «glandis», VI, 2, col. 2033, 11-29).

25. «QUE HAY QUE PERSEVERAR ANTE LO QUE NOS APREMIA. Resiste la palmera el peso y se alza en arco, / y cuanto más la apremia la carga más la levanta: / lleva perfumados frutos, dulces postres, / que en las mesas ocupan el lugar de honor. / Ve, muchacho, y ascendiendo por las ramas recógelos: quien a su propósito / sea fiel, logrará dignos premios» (trad. de F. García Jurado). 
De esta forma, «Lleva la palma» nos presenta un caso parecido al del aforismo Usque ad aras, pues si bien debe partirse de un texto de Aulo Gelio, el aforismo como tal no aparece en las N.A.

\title{
4.3. "No huye el que se retira»
}

La prudencia es una virtud que a veces puede confundirse con la cobardía, mientras que, por otro lado, lo que parece valentía a menudo no es más que simple temeridad. En consecuencia, la valentía debe basarse en la prudencia. Esta enseñanza da lugar a una nueva frase de carácter aforístico que ha llamado la atención de los comentaristas: «No huye el que se retira -respondió don Quijote-, porque has de saber, Sancho, que la valentía que no se funda sobre la basa de la prudencia se llama temeridad, y las hazañas del temerario más se atribuyen a la buena fortuna que a su ánimo» (Quijote II, 28 [Rico $2005,767])$. Este argumento acerca de la diferencia que hay entre la temeridad y la prudencia recuerda a Rodríguez Marín una frase citada por Aulo Gelio a propósito de Demóstenes (Gelio 17, 21), y así lo hace ver en la nota correspondiente:

\begin{abstract}
Demóstenes, que se halló en la batalla de Filipo contra los atenienses, buscó la salvación en la fuga; y, censurado por cobarde, respondió citando un verso entonces muy conocido: «El que huye podrá pelear aún». Así se lee en el cap. xxi del libro XVII de las Noches áticas de Aulo Gelio (Rodríguez Marín 1948, V, 279).
\end{abstract}

Rodríguez Marín recurre de nuevo a la traducción de Navarro y Calvo, donde, como ya sabemos, no figuran los parágrafos, de manera que lo que cita como el capítulo vigésimo primero del libro decimoséptimo debe remitirse, de manera más concreta, al parágrafo 31, que en la traducción de Navarro y Calvo es como sigue:

Demóstenes deja el campo de batalla y busca la salvación en la fuga; censúranle su cobardía, y responde citando este verso tan conocido: «El que huye podrá pelear aún» (Gelio 17, 21, 31 [apud Gelio 1891, II, $205-206])^{26}$.

Estamos, pues, ante una nota a Gelio que oscila entre el tópico y la cita de apoyo documental.

26. Tum Demosthenes orator ex eo proelio salutem fuga quaesivit, cumque id ei quod fugerat

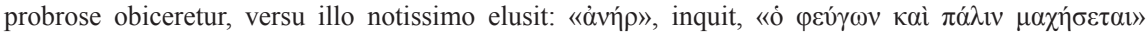
(Gelio 17, 21, 31). 


\section{4. «Si dijere mentira»}

Uno de los aspectos por los que Gelio ha sido más citado es el de los problemas lógicos que, como él mismo nos recuerda, se planteaban durante las discusiones simposiacas. El asunto se convierte en un recurrente motivo para la literatura posterior. Verdaderos dilemas, también llamados «argumentos recíprocos», los problemas lógicos de difícil solución han atraído la atención de muchos autores y han llegado incluso al propio Jorge Luis Borges, quien en su prólogo al libro Matemáticas e imaginación recurre a autores como Gelio, Cervantes o Bertrand Russell para dar cuenta de lo que no deja de ser una dilatada tradición dialéctica:

Aulo Gelio (Noches áticas, libro quinto, capítulo X) recurre a un orador y a su alumno; Luis Barahona de Soto (Angélica, onceno canto), a dos esclavos; Miguel de Cervantes (Quijote, segunda parte, capítulo LI), a un río, a un puente y a una horca; Jeremy Taylor, en alguno de sus sermones, a un hombre que ha soñado con una voz que le revela que todos los sueños son vanos; Bertrand Russell (Introduction to Mathematical Philosophy, página 136), al conjunto de todos los conjuntos que no se incluyen a sí mismos (Borges, «Edward Kasner and James Newman: Mathematics and the Imagination [Simon and Schuster]», en Discusión [1932] [apud Borges 1989, I, 276]).

El recuerdo de esta tradición de plantear problemas lógicos insolubles aflora en las páginas del Quijote cuando Sancho, durante su gobierno, es puesto a prueba para que resuelva uno de estos complejos casos: «Si alguno pasare por esta puente de una parte a otra, ha de jurar primero adónde y a qué va; y si jurare verdad, déjenle pasar, y si dijere mentira, muera por ello ahorcado en la horca que allí se muestra, sin remisión alguna» (Quijote II, 51 [Rico 2005, 939]). A partir de tales premisas, el problema se plantea cuando alguien con la intención de pasar por el puente afirma que había acudido allí para ser ahorcado, con lo cual, al decir verdad, no era posible su ahorcamiento; sin embargo, al no cumplir con el castigo, se volvía mentira lo que había sido dicho como verdad. Schevill y Bonilla apuntan a Pedro Mexía (Silva 1, 18) como posible inspirador de la paradoja ${ }^{27}$ :

Pero Mexía, en su Silva de varia lección refiere un pleito que hubo entre un discípulo y su maestro, «tan subtil y dudoso» que los jueces no supieron determinarlo; y queda la determinación al juicio del discreto lector. -edic. Bibliof. esp., I, 115; lo mismo en Pauli, op. cit., 119; nuestra «pregunta» encaja mal en el gobierno de Sancho y parece traída por los cabellos (Schevill-Bonilla 1941, X, 435).

27. Para la relación entre Cervantes y Pedro Mexía véase el trabajo ya clásico de Castillo 1945. 
El pleito entre el discípulo y su maestro que refiere Mexía no es otro que el del litigio que Protágoras entabló contra su discípulo Evatlo, tal como encontramos en Gelio 5, 10. Evatlo había pagado a Protágoras la mitad del importe de su formación, con la condición de que, una vez terminado el período de enseñanza, satisficiera a su maestro la otra mitad restante tras ganar su primer pleito. Como el discípulo tardaba en cumplir con lo convenido, el maestro decidió por cuenta propia entablar un pleito con aquel, en la idea de que, si le ganaba el litigio al alumno, este tendría que pagarle según la sentencia, y, en caso de perderlo, también, de acuerdo a lo convenido. Pero el alumno replicó dando la vuelta a tales argumentos, de manera que, si fuera él quien ganara el pleito, nada tendría que pagarle al maestro según la sentencia $\mathrm{y}$, en caso de perderlo, tampoco, de acuerdo a lo convenido.

La nota que encontramos en Rico parte de la de Schevill-Bonilla, si bien llega ahora hasta el texto de Gelio donde se inspira Mexía; sorprende, sin embargo, que en la nota se afirme que en Gelio 5, 10 se recuerda a Plinio, cuando en realidad Gelio no lo menciona en tal capítulo: «SB señala como fuente remota a Mexía, Silva, I, pp. 338-341, quien a su vez encuentra paralelos con un episodio contado por Aulo Gelio en las Noches áticas, V, 10, en que recuerda a Plinio» (Rico 1998, nota complementaria a 1045.5). No obstante, hay que seguir leyendo el texto de Mexía para encontrar un nuevo capítulo de las N.A. (Gelio 9, 16) donde, en efecto, se habla acerca de Plinio el Viejo y de su interés por los llamados argumentos «recíprocos»: «El mismo Aulo Gelio, en el postrero capítulo del nono libro, escribe otro pleito o argumento semejante al ya dicho, refiriendo a Plinio, que lo cuenta» (Mexía, Silva 1, 18 [apud Mexía 2003, 146]). Aunque tales episodios, en especial el de Protágoras y Evatlo, sean bien conocidos, Rodríguez Marín no recurre a ellos en su nota correspondiente al pasaje del Quijote, sino que, de una manera más precisa, parte del uso específico de la expresión «decir mentira» que encontramos en el pasaje cervantino para referirse a Gelio 18, 2:

La cuestión es muy parecida a una de aquellas en cuyo esclarecimiento se ocupaban en Atenas, celebrando las Saturnales, Aulo Gelio y otros romanos con sus maestros: «Mentir y decir que se miente, ees decir mentira, o verdad?» (Noches áticas, lib. XVIII, cap. ii). Como insinué en el cap. xlv (t. VII, 26, 8), los casos litigiosos sometidos a la deliberación de Sancho traen a la memoria, entre otros, los de aquellas justicias de Medoro que cuenta Barahona en el canto xi de La Angélica (Rodríguez Marín 1948, VII, 145).

Como en ocasiones anteriores, Rodríguez Marín vuelve a citar la versión castellana de Navarro y Calvo: «También se preguntaba: "Qué debe responderse á esta pregunta: Mentir y decir que se miente, ¿es decir mentira o verdad?"»(Gelio 18, 2, 10 [apud Gelio 1893, II, 212]) 28. Por lo que puede

28. Quaesitum ibi est quae esset huius quoque sophismatis resolutio: «Cum mentior et mentiri me dico, mentior an verum dico?» (Gelio 18, 2, 10). 
apreciarse en otro pasaje de Gelio que luego es recogido igualmente por Mexía y, por medio de este, llega al mismo Montaigne, hay una diferencia significativa entre el acto de «mentir», donde está implicada la conciencia e intención de tal acto, y la acción de «decir mentira», donde simplemente se afirma algo que no responde a la verdad ${ }^{29}$.

Como podemos observar, en este caso, los correlatos posibles entre el pasaje de Cervantes y el texto de Gelio son varios.

\subsection{El llanto del heredero}

El tópico de la herencia que alegra al heredero, a pesar de su apariencia de tristeza, es recordado ya casi al final de la novela: «... que esto del heredar algo borra o templa en el heredero la memoria de la pena que es razón que deje el muerto» (Quijote II, 74 [Rico 2005, 1104]). Dentro de una extensa nota, Rodríguez Marín recuerda que el tópico aparece en Gelio 18, 14, aunque, en realidad, la cita correcta sea Gelio 17, 14. Se trata de un breve capítulo donde Aulo Gelio recopila algunas sentencias del mimógrafo latino Publilio Siro, a quien Rodríguez Marín transcribe como «Publio Syro», tal como se hace en la versión española de Navarro y Calvo. No obstante, Rodríguez Marín cita la sentencia en lengua latina, que en la versión de Navarro y Calvo se traduce como «Lágrimas de heredero, risa oculta» (Gelio 1893, II, 196):

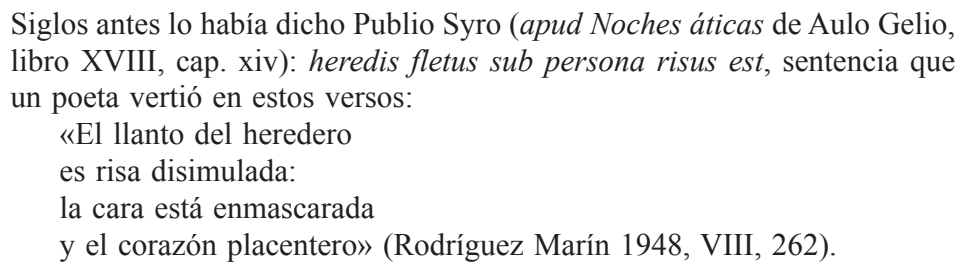

Probablemente, al libro XVII de las Noches áticas, indicado mediante números romanos, se ha añadido por equivocación una unidad más. De manera precisa, la cita de la sentencia recogida sería Gelio 17, 14, 4, si le añadimos el parágrafo. Por su parte, en la edición de Rico se sigue explícitamente la nota de Rodríguez Marín y, a pesar de que en ella se actualiza el nombre del autor latino (en lugar de «Publio Syro», tal como cita Rodríguez Marín, ahora se escribe «Publilio Siro»), se reproduce la errata concerniente al número del libro:

RM cita a Hartzenbusch y remite el lugar común a Publilio Siro, citado en las Noches áticas, de Aulo Gelio, XVIII, 14: «Heredis fletus sub persona

29. Acerca de la expresión «decir mentira»y su diferencia con «mentir» tenemos Gelio 11, 11, texto que desde Mexía es referido luego por Montaigne en su ensayo «Des menteurs» (García Jurado 2012b). 
risus est»; pueden verse también los afines que trae Tosi [1991: núms. 223225] (Rico 1998, nota complementaria a 1221.35).

Las sentencias de Publilio Siro tuvieron una gran transcendencia en la cultura humanística, sobre todo gracias a la edición que de ellas llevó a cabo Erasmo de Róterdam (Bravo de Laguna Romero y Rodríguez Herrera 2018).

\subsection{Ciudades de Grecia y Homero}

Finalmente, encontramos un nuevo correlato con Gelio cuando llegamos al tópico de las ciudades que pugnaron por ser la patria de Homero; mediante este tópico, Cervantes da cuenta de la indeterminación del lugar de $\mathrm{La}$ Mancha del que era originario don Quijote:

Este fin tuvo el Ingenioso Hidalgo de la Mancha, cuyo lugar no quiso poner Cide Hamete puntualmente, por dejar que todas las villas y lugares de la Mancha contendiesen entre sí por ahijársele y tenérsele por suyo, como contendieron las siete ciudades de Grecia por Homero (Quijote II, 74 [Rico 2005, 1104]).

Rodríguez Marín se refiere a un dístico latino, sin mayores especificaciones al respecto:

Smyrna, Rhodos, Colophon, Salamis, Chios, Argos, Athenae,

Orbis de patria, certat, Homere tua (Rodríguez Marín 1948, VIII, 265) 30. $^{30}$

En lo que a este asunto respecta, resulta muy interesante la nota que nos ofrece Martín de Riquer ${ }^{31}$ : «Los antiguos suponían que siete ciudades helenas pretendían ser la patria de Homero. El epigrama 297 del libro IV de la Antología de Planudes las enumera: Cime, Esmirna, Quíos, Colofón, Pilos, Argos y Atenas» (Riquer 1980, 1137). Máximo Planudes es un erudito bizantino que compila una selección de poemas (la Antología Planúdea propiamente dicha), si bien luego ha pasado a ser el libro XVI de lo que conocemos como la Antología Palatina o Antología Griega (Greek Anthology 1918). De manera particular, Riquer selecciona el epigrama que lleva el número 297 de la antología:

30. «Esmirna, Rodas, Colofón, Salamina, Quíos, Argos, Atenas, / el orbe disputa, Homero, por ser tu patria» (trad. de F. García Jurado).

31. No es, sin embargo, la nota de carácter mucho más general que podemos encontrar en su primera edición del Quijote, la de 1944: «Sobre ser la patria de Homero contendían Cumas, Esmirna, Quíos, Colofón, Pilos, Argos y Atenas» (Riquer 1944, 1072, n. 6). La relación de ciudades da a entender que Riquer ya partía del epigrama de Planudes, aunque sin citarlo todavía. 


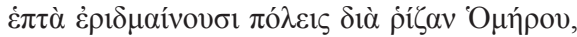

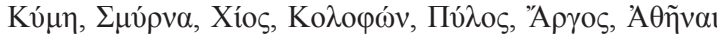
(Antología Palatina 16, 297 [Greek Anthology 1918, 338-339]) ${ }^{32}$

La edición de Rico, en nota complementaria, sigue básicamente la nota de Martín de Riquer, aunque desarrolla un aspecto nuevo en relación con Gelio:

CT; RM cita un dístico latino; RQ, el epigrama 297 de la antología de Planudes. Sin embargo, la enumeración más extendida en aquel momento procedía de Aulo Gelio: «Septem urbes certant de stirpe insignis Homeri: Smyrna, Rhodos, Colophon, Salamin, Chius, Argos, Athenae» (Noches áticas, II, 10) (Rico 1998, nota complementaria a 1222.42).

Esta referencia a Gelio 2, 10 no tiene fundamento alguno. Claramente se trata de un error, pues los versos citados no pertenecen al asunto tratado en tal capítulo: «Cuál es el sentido de las palabras favissae (sic) Capitolinae (cuevas Capitolinas). Respuestas de M. Varrón a Servio Sulpicio, que le consultaba acerca de ellas» (Gelio 2, 10 apud Gelio 1893, I, 81) ${ }^{33}$. Pero si acudimos a un texto de Jacques Joset (uno de los responsables de las notas de la edición de Rico) acerca del uso de este tópico tanto por parte de Cervantes como de Montaigne, observamos que la referencia correcta es Gelio 3, 11:

A este acervo cultural de época pertenece, por ejemplo, la contienda de las siete ciudades griegas sobre el lugar de nacimiento de Homero en las páginas finales del Quijote, II, 74, 1335 («como contendieron las siete ciudades de Grecia por Homero»), y su recuerdo en Los Ensayos (II, 36, 791): «Sept villes Grecques entrerent en debat du lieu de sa naissance...». Ambos por separado recordaban un verso de las Noches áticas, III, 11, de Aulo Gelio (h. 130-h. 180): «Septem urbes certant de stirpe insignis Homeri» (Joset 2017, 523).

Si nos atenemos a la referencia que nos da Joset, el texto de Gelio sería el siguiente:

Menos de acuerdo todavía se está acerca de la patria de Homero. Pretenden unos que nació en Colofón, otros que en Esmirna; algunos le hacen ateniense, otros egipcio. Aristóteles le da por patria la isla de Yos. M. Varrón, en el primer libro de sus Imágenes, coloca estos versos bajo el retrato de Homero: «Esta cabra blanca indica el punto en que descansa Homero; porque una cabra blanca es la víctima que ofrecen los habitantes de Yos en sacrificio a su memoria».

(Gelio 3, 11, 6-7 [apud Gelio 1983, I, 142]) ${ }^{34}$

32. «Siete ciudades disputan por ser la cuna de Homero: / Cumas, Esmirna, Quíos, Colofón, Pilos, Argos y Atenas» (trad. de F. García Jurado).

33. Quid sint favisae Capitolinae; et quid super eo verbo M. Varro Servio Sulpicio quaerenti rescripserit (Gelio 2, 10).

34. De patria quoque Homeri multo maxime dissensum est. Alii Colophonium, alii Smyrnaeum, sunt qui Atheniensem, sunt etiam qui Aegyptium fuisse dicant, Aristoteles tradidit ex insula Io. M. Varro in libro De Imaginibus primo Homeri imagini epigramma hoc apposuit. 
Sin embargo, como podemos ver, este no es el texto citado por Joset en su ensayo. La falta de correspondencia encuentra su explicación gracias al hecho de que en las antiguas ediciones, hasta el mismo siglo XIX, a este texto de Gelio 3, 11 se añadían los dos versos siguientes acerca de las siete ciudades que se disputaban la patria de Homero $^{35}$ :

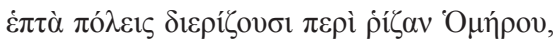

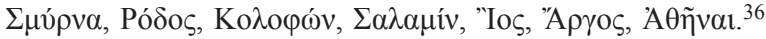

Estos versos a veces aparecen junto con su traducción latina, que es la que se cita en la nota de la edición de Rico:

Septem urbes certant de stirpe insignis Homeri:

Smyrna, Rhodos, Colophon, Salamin, Ios, Argos, Athenae. ${ }^{37}$

Esta circunstancia dio lugar al malentendido de que se pensara que era realmente Aulo Gelio quien había recogido tales versos, lo que provoca que, por ejemplo, ya lo encontremos referido en los márgenes del ensayo 2, 36 de Montaigne al menos desde una edición de $1619^{38}$. Lo que se está citando en la edición de Rico es, pues, aquello que figura como texto de Gelio en las antiguas ediciones de las $N$. A. Podemos comprobar cómo todavía tales versos aparecen en la versión española de Navarro y Calvo: «Siete ciudades se disputan el honor de haber dado a luz Homero: Esmirna, Rodas, Colofón, Salamina, Yos, Argos y Atenas» (Gelio 3, 11, 7 [apud Gelio 1893, I, 142]). De esta forma, vuelve a ser muy pertinente la necesidad de recurrir a modernas ediciones de Gelio a la hora de citarlo.

35. Holford-Strevens apunta, en lo que respecta a la editio princeps llevada a cabo por Bussi en 1469: «(as in some recentiores) a recension of the Greek distich of Homer's disputed birthplace [was appended] to 3.11» (Holford-Stevens 2005, 341).

36. «Siete ciudades disputan por ser la cuna de Homero, / Esmirna, Rodas, Colofón, Salamina, Íos, Argos, Atenas» (trad. de F. García Jurado).

37. «Siete ciudades disputan por ser la cuna del insigne Homero: / Esmirna, Rodas, Colofón, Salamina, Íos, Argos, Atenas» (trad. de F. García Jurado).

38. «Noc. Att. 1. 3. C. II» (Montaigne 1619, 724), formulada la cita con una numeración que algunos podrían interpretar como Gelio 3, 11 o Gelio 3, 2, con la consiguiente cascada de referencias erróneas, que llega hasta la propia edición de las obras completas publicadas en la colección La Pléiade (Montaigne 1992). 


\section{UnAS CONCLUSIONES. EL QUIJOTE VISTO DESDE LAS NOCHES ÁTICAS}

... la cultura es la capacidad de situar los libros en la biblioteca colectiva y de situarse en el interior de cada libro (Bayard 2011, 49).

Tras este recorrido por los pasajes del Quijote susceptibles de poder plantear algún correlato con las N.A., cabría matizar el texto de Marasso citado al comienzo de este trabajo para afirmar que Gelio no es un autor necesariamente leído por Cervantes, si bien este pudo aprender algunas cosas de la obra de aquel. Cervantes no leyó jamás las N.A. o, cuando menos, es muy improbable que las leyera o incluso hojeara. A lo más, pudo leer la referencia a la miscelánea latina en las páginas de Guevara o Mexía. Sin embargo, esta circunstancia no fue óbice para que una obra tan referida por tales autores pudiera llegar a entreverse, siquiera esporádicamente, en el Quijote. Para ello, el desarrollo de los seis criterios heurísticos que hemos presentado al comienzo de este trabajo, así como la idea de los correlatos, ha resultado clave. De igual manera, también ha sido fundamental la decisión de incluir las notas de los cervantistas como parte del objeto del presente estudio. Vamos a revisar a continuación los seis criterios heurísticos propuestos al comienzo, ahora a partir del análisis llevado a cabo:

a. Los intermediarios. Los intermediarios fundamentales entre las N.A. y el Quijote son los esperables: Fray Antonio de Guevara y Pedro Mexía sobresalen en este cometido, si bien, por ejemplo, al señalar la noticia de la cortesana Laida, Clemencín se queda únicamente en Fray Antonio de Guevara, sin indicar que este toma la noticia de Gelio (3.1.). Esta posibilidad de retrotraerse hasta Gelio abre las puertas a nuevas lecturas cervantinas de la obra de Guevara que pudieran conducirnos hasta otros pasajes gelianos, como el de Androcles y el león. En lo que respecta a Mexía, sí es más común que los comentaristas lleguen hasta Gelio (4.4.). Por lo demás, tanto Erasmo con sus adagios (3.4.) como Alciato con sus emblemas (4.2.) han podido ser, gracias a su fama y difusión, eficaces y esporádicos intermediarios entre Gelio y Cervantes.

b. Pruebas materiales. En lo que respecta a Cervantes, si bien este jamás leyó las N.A., contamos curiosamente con una edición que se publicó entre la primera y la segunda parte del Quijote: se trata de una edición de Stephanus, concretamente, la editio ginebrina de 1609 (Gelio 1609). De manera significativa, si bien para Cervantes no nos consta prueba material alguna, sí hemos podido averiguar el texto que utilizó uno de sus principales comentaristas, Rodríguez Marín, y que no es otro que la versión española de Francisco Navarro y Calvo (Gelio 1893, I y II). Se trataría, por tanto, de una prueba material indirecta (3.2.; 4.3.; 4.4.; 4.5.).

c. Citas y paráfrasis. Al no haberse dado una lectura directa de la obra, no contamos en Cervantes con tales citas, ni tan siquiera como paráfrasis. No obstante, a tenor de la prueba material de la versión española de Aulo Gelio utilizada por Rodríguez Marín, sí podemos encontrar pequeños pasajes citados por el crítico, en algunos casos a manera de apoyo documental, como cuando se trata 
de la prosodia del nombre «Anibal» (3.2.). Merece la pena, en lo que a las citas de los comentaristas respecta, señalar los errores cometidos, bien a causa de las erratas $(4.5 . ; 4.6$.), pero, sobre todo, a causa de no comprobar lo que se está citando, de interpretar erróneamente los datos ofrecidos por otros autores (3.4.; 4.1.; 4.2.) o, simplemente, de citar a partir de una antigua edición de Gelio (4.1.; 4.6.).

d. Lugares comunes y tópicos. La obra de Gelio cuenta con una serie de temas y tópicos que han transcendido el ejercicio de la mera lectura directa. Nos referimos a anécdotas e historias que perfectamente han podido ser relatadas por otros autores, como la noticia de la cortesana Laida (3.1.) y, quizá, la historia de Androcles y el león (3.1.). De manera particular, los argumentos recíprocos (4.4.), así como expresiones del tipo «no huye el que se retira» (4.3.), «decir mentira» (4.4.) o el lugar común relativo a las siete ciudades de Homero (4.6.) constituyen tópicos notables que vienen a tener sus correlatos más o menos lejanos en Aulo Gelio.

e. Aforismos. Ciertos aforismos utilizados por Cervantes, según algunos críticos, encuentran su correlato en Aulo Gelio, aunque este aspecto exige una revisión profunda acerca de aquello que realmente ha escrito Gelio. De manera especial, deben revisarse los adagios usque ad aras (3.4.) y «llevarse la palma» (4.2.), pues son fruto de varios errores de transmisión y no aparecen, al menos tal cual son citados, dentro de las $N$. A. Por nuestra parte, hemos propuesto el correlato entre Veritas filia temporis de Gelio con «La verdad, cuya madre es la historia» en Cervantes (3.3.), sobre todo, considerando ambas frases en su proyección histórica, la primera a partir de Francis Bacon, que la orienta hacia el empirismo, y la segunda a partir de Borges, que le imprime un sentido pragmatista.

f. Géneros literarios: entre la miscelánea y el ensayo. La conciencia de la obra de Gelio en calidad de libro abierto ha convertido su variado contenido en algo susceptible de pasar a otros contextos y lugares. Enseñanzas morales, anécdotas o silogismos se han integrado en el acervo común de la cultura de una época, y la novela cervantina se muestra claramente deudora de esta modalidad de erudición relajada de la que son excepcionales representantes el antiguo Gelio y el moderno Mexía. A su vez, Cervantes plantea en algunos de sus prólogos (3.1.) apreciaciones que ya lo proyectan a desarrollos propiamente ensayísticos, a la manera de los de Montaigne, autor a quien, al igual que ocurre con Gelio, tampoco leyó Cervantes.

\section{FUENTES}

Alciato. 1975. Emblemas. Prólogo de Manuel Montero Vallejo, preparación de textos y notas, Mario Soria. Madrid: Editora Nacional.

Bacon, Francis. 1803. The Works of Francis Bacon, vol. VIII. Londres: J. Johnson.

Borges, Jorge Luis. 1989. Obras completas I-III. Barcelona: Emecé.

Clemencín, Diego, ed. 1967. Miguel de Cervantes, El ingenioso hidalgo Don Quijote de la Mancha I-VI. Madrid: Castilla (1. ${ }^{\mathrm{a}}$ ed. Madrid: Aguado, 1935). 
Erasmo de Rotterdam. 2001. Les adages, vol. 3, dir. Jean-Christiphe Saladin. París: Les Belles Lettres.

Gelio, Aulo. 1609. Auli Gellii Noctes Atticae seu Vigiliae Atticae ad exemplar potissimum Henrici Stephani lucidiores redditae; Quas nunc primum a magno mendorum numero magnus veterum exemplarium numerus repurgavit. Aureliae Allobrogum (Ginebra): Apud Samuelem Crispinum.

Gelio, Aulo. 1871-1877. Noctium Atticarum libri XX. Ex recensione Martini Hertz. I-II. Lipsiae: Teubner.

Gelio, Aulo. 1893. Noches áticas, trad. Francisco Navarro y Calvo, I-II. Madrid: Biblioteca Clásica.

Gelio, Aulo. 1927. The Attic Nights of Aulus Gellius, with an English Translation by John C. Rolfe. Cambridge, Mass.: Harvard University Press; Londres: William Heinemann Ltd.

Greek Anthology. 1918. The Greek Anthology, vol. 5, with an English Translation by W. R. Paton. Cambridge, MA: Harvard University Press.

Guevara, Fray Antonio de. 1994. Relox de príncipes, estudio y edición de Emilio Blanco. Madrid: ABL.

Guevara, Fray Antonio de. 2004. Obras completas, III. Epistolas familiares, ed. y pról. Emilio Blanco. Madrid: Fundación José Antonio de Castro.

Huarte de San Juan, Juan. 1989. Examen de ingenios, ed. Guillermo Serés. Madrid: Cátedra. Macrobio. 2010. Saturnales, introd., trad. y notas de Fernando Navarro Antolín. Madrid: Gredos. Mexía, Pedro. 2003. Silva de varia lección, ed. Isaías Lerner. Madrid: Castalia.

Montaigne, Michel de. 1619. Les Essais de Michel seigneur de Montaigne. Édition nouvelle enrichie d'annotations en marge. Corrigée \& augmentée d'un tiers outre les precedentes impressions, etc. Rouen: Jacques Besongne.

Montaigne, Michel de. 1992. Oeuvres completes, textes établis par Albert Thibaudet et Maurice Rat, introduction et notes par Maurice Rat. París: Gallimard.

Rico, Francisco, ed. 1998. Miguel de Cervantes, Don Quijote de la Mancha. Edición del Instituto Cervantes dirigida por Francisco Rico. Barcelona: Crítica.

Rico, Francisco, ed. 2005. Miguel de Cervantes, Don Quijote de la Mancha, edición del IV Centenario. Madrid: Real Academia Española.

Riquer, Martín de, ed. 1944. Miguel de Cervantes, Don Quijote de la Mancha, edición y notas Martín de Riquer. Barcelona: Juventud.

Riquer, Martín de, ed. 1980. Miguel de Cervantes, El ingenioso hidalgo Don Quijote de la Mancha. Barcelona: Planeta.

Rodríguez Marín, Francisco, ed. 1947-1949. Miguel de Cervantes, El ingenioso hidalgo Don Quijote de la Mancha, nueva ed. crítica, I-X. Madrid: Atlas.

Schevill, Rudolf y Adolfo Bonilla, eds. 1928-1941. Obras completas de Miguel de Cervantes Saavedra, I-IV. Madrid: Gráficas Reunidas.

Suetonio. 1964. Vida de los doce Césares, texto revisado y traducido por Mariano Bassols de Climent, vol. I (lib. I-II). Barcelona: Alma Mater.

\section{BIBLIOGRAFÍA CITADA}

Baker, Edward. 1997. La biblioteca de don Quijote. Madrid: Marcial Pons.

Barbagallo, Antonio. 2001. «El Quijote verosimilitud en la ficción o la ficción de la verdad». En Volver a Cervantes. Actas del IV Congreso Internacional de la Asociación de Cervantistas, Lepanto 1/8 de octubre de 2000, vol. 1, ed. Pablo Bernat Vistarini, 553-572. Palma: Universitat de les Illes Balears. 
Barnés, Antonio. 2009. «Yo he leído en Virgilio». Análisis sincrónico de la tradición clásica en el Quijote. Vigo: Academia del Hispanismo.

Bataillon, Marcel. 1998. Erasmo y España. Estudios sobre la historia espiritual del siglo XVI. México: Fondo de Cultura Económica (primera edición de 1937).

Bausi, Francesco. 2016. "“Veritas filia temporis". Machiavelli e le citazioni a chilometro zero». Parole Rubate. Rivista Internazionale di Studi sulla Citazione 7: 77-87.

Bayard, Pierre. 2011. Cómo hablar de los libros que no se han leido. Barcelona: Anagrama.

Bizzarri, Hugo. 2015. Diccionario de paremias cervantinas. Alcalá de Henares: Universidad de Alcalá.

Bravo de Laguna Romero, Francisco y Gregorio Rodríguez Herrera. 2018. «Las Sententiae de Publilio Siro seleccionadas por Erasmo y su influencia en los florilegios de G. Maior y A. Rodrigues de Évora». Cuadernos de Filología Clásica (Estudios Latinos) 38: 83107.

Castillo, Carlos. 1945. «Cervantes y Pero Mexía». Modern Philology 43(2): 94-106.

Cherchi, Paolo. 1993. «Sobre las fuentes de la Silva de Pedro Mexía». Revista de Filología Española 73: 43-53. https://doi.org/10.3989/rfe.1993.v73.i1/2.554

Eisenberg, Daniel. 1987. «La biblioteca de Cervantes». En Studia in honorem prof. Martín de Riquer, II, 271-328. Barcelona: Quaderns Crema.

Faselius, August. 1859. Latium oder das alte Rom in seiner Sprüchwörten: eine Sammlung. Weimar: Benhard Friedrich Boigt.

Fuente Marina, Beatriz de la. 2019. «Las citas de origen latino en el Quijote». Parole Rubate. Rivista Internazionale di Studi della Citazione 19: 117-145.

García Jurado, Francisco. 2012a. «Aulo Gelio y la literatura española del siglo XVI: autor, texto, comentario y relectura moderna». Revista de Literatura 74: 31-64.

García Jurado, Francisco. 2012b. «"Mentir" y "Decir mentira”. Una differentia entre la miscelánea de Aulo Gelio y el ensayo de Montaigne». Atene e Roma 6: 1-20.

García Jurado, Francisco. 2017a. «Apuntes sobre el Inca Garcilaso y su lectura de Aulo Gelio (notas de viaje)». Reinventar la Antigüedad. Accesible en: <https://clasicos. hypotheses.org/2676>. Fecha de acceso: 3 de marzo de 2021.

García Jurado, Francisco. 2017b. «Plutarchus noster, "nostre Plutarque": Aulu-Gelle, Montaigne, Amyot et Goulart». Latomus. Revue d'Études Latines 76(2): 463-480.

Gendrickson, George L. 1957. «Amici usque ad aras». The Classical Journal 45: 395-397.

Holford-Strevens, Leofranc. 2004. «Recht as een Palmen-Bohm and Other Facets of Gellius' Medieval and Humanistic Reception». En The Worlds of Aulus Gellius, eds. Leofranc Holford-Strevens y Amiel Vardi, 249-281. Oxford: Oxford University Press.

Holford-Strevens, Leofranc. 2005. Aulus Gellius. An Antonine Scholar and his Achievement. Oxford: Oxford University Press.

Magnien-Simonin, Catherine. 1995. «Montaigne et Aulu-Gelle». Bulletin de la Société des Amis de Montaigne 41(2): 7-23.

Mainer, José Carlos. 1996. «Apuntes junto al ensayo». En El ensayo español, tomo I, 9-33. Barcelona: Crítica.

Marasso, Arturo. 1954. Cervantes. La invención del Quijote. Buenos Aires: Hachette.

Monterroso, Augusto. 2003. Literatura y vida. Madrid: Alfaguara.

Navarro Antolín, Fernando. 2006. «Cervantes y la tradición clásica». En 4 siglos os contemplan. Cervantes y el Quijote, ed. Javier Blasco, 149-186. Madrid: Eneida.

Palomares Expósito, Caty y José Palomares Expósito. 2008. «Silva aurea: glosas al Quijote, La picara Justina y las Flores de poetas ilustres». En Cervantes y su tiempo, eds. Juan Matas Caballero y José María Balcells Doménech, tomo II, 259-261. León: Universidad de León. 
Ramírez-Araujo, Alejandro. 1954. «Usque ad aras amicus. Un adagio glosado por Cervantes». Hispanic Review 22(3): 224-227.

Schwartz, Lia. 2005. «El Quijote en la obra crítica de Arturo Marasso». Olivar 6(6): 43-58.

Solís de los Santos, José. 2012. «150. Aulo Gelio. BUS A 335/086(2): A. Gellii Noctes Atticae (Venecia: Cristoforo Quaietis \& Martino Lazzaroni, 1493)». En La Antigüedad en el Fondo Antiguo de la Biblioteca de la Universidad de Sevilla, coords. José Beltrán Fortes y Eduardo Peñalver Gómez, 350-352. Sevilla: Secretariado de Publicaciones de la Universidad.

Solís de los Santos, José. 2016. «Cervantes y el entorno humanista de los Ramírez de Prado». Edad de Oro 35: 97-120.

Thesaurus linguae Latinae. 1900-. Leipzig-Múnich: Teubner-Bayerischen Akademie der Wissenschaften. Accesible en: <http://www.thesaurus.badw.de/en/tll-digital/tll-openaccess.html>. Fecha de acceso: 3 de marzo de 2021.

Recibido: 7 de octubre de 2019 Aceptado: 1 de febrero de 2020 